\title{
IMPLEMENTASI PROGRAM KELUARGA HARAPAN DALAM UPAYA MENGENTASKAN KEMISKINAN DI KOTA BATU
}

\author{
Cahyo Sasmito \\ Universitas Tribhuwana Tungga Dewi Malang, Email : cahyosasmito1970@gmail.com \\ Ertien Rining Nawangsari \\ Universitas Pembangunan Nasional Veteran Jawa Timur, Email : ertien.riningnawangsari@ yahoo,com
}

\begin{abstract}
This research was conducted from February to April 2018 with qualitative descriptive methods. The data sources consist of: primary data sources and secondary data sources, primary data sources obtained from observations, and interviews. Interview with informants (purposive sampling) based on the interview guides as instruments, and the researchers as research instruments. While secondary data is obtained from documentation. Data analysis used the Miles and Huberman models of Sugiyono, 2017 whose activities include: data reduction, data display and conclution drawing / verification.

The results of this study, the implementation of the Keluarga Harapan Program (PKH) effort to alleviate poverty in the Social Service Office of Batu City has been going well. Communication is established well with PKH Facilitators, and PKH Participants. The Social Service involves the Facilitators in meetings coordination, as provisions for improving professionals seminars and matrices in to help the Facilitators to assist PKH Participants in providing counseling to tell the terms and conditions that must be fulfilled by the Participants.

The Government's Social Service of Batu City has exercised its authority both from aspects: communication, resources, disposition, and bureaucratic structure with PKH Assistants in the implementation to alleviate the PKH Participants' poverty. Therefore the implementation is being well because of the determined terms and conditions in education terms (permanent school participants) and in the health terms (long term health insurance), so that social assistance through PKH cash can be received by the Participants through the BNI account of each PKM Participant. Furthermore, the PKH Assistants help the Participants to counseling provide to PKH Participants in skills possessed develop by the each Participant. Therefore, for the long term PKH implementation in poverty alleviation efforts will be able to be realized by the Government's Social Service of Batu City.
\end{abstract}

Keywords: assistance processing, developing skills, alleviating poverty 



\begin{abstract}
ABSTRAK
Penelitian ini dilaksanakan pada bulan Februari sampai dengan April 2018 dengan metode deskriptif kualitatif. Sumber data terdiri dari: sumber data primer dan sumber data sekunder, sumber data primer diperoleh dari hasil pengamatan, dan wawancara. Wawancara dengan informan (purposive sampling) berdasarkan interview guide sebagai instrumen, peneliti sebagai instrumen penelitian. Data sekunder diperoleh dari dokumentasi. Analisis data menggunakan model Miles dan Huberman dalam Sugiyono, 2017 yang aktivitasnya meliputi: data reduction, data display, dan conclution drawing/verification.

Hasil penelitian ini, bahwa implementasi Program Keluarga Harapan (PKH) dalam upaya mengentaskan kemiskinan pada Dinas Sosial Pemerintahan Kota Batu telah berjalan dengan baik dan lancer. Komunikasi terjalin secara baik dengan Pendamping PKH, dan Peserta PKH. Dinas Sosial melibatkan Pendamping PKH dalam rapat koordinasi, seminar dan matrikasi sebagai bekal untuk meningkatkan professional dalam implementasi PKH dalam upaya mengentaskan kemiskinan. Dinas Sosial memberikan tugas pada Pendamping PKH untuk membantu Peserta PKH dalam memberikan penyuluhan terkait syarat dan ketentuan wajib yang harus dipenuhi Peserta PKH.

Dinas Sosial Pemerintah Kota Batu telah menjalankan kewenangannya baik dari aspek: komunikasi, sumber daya, disposisi, dan struktur birokrasi mengandeng Pendamping PKH dalam implementasi PKH untuk mengentaskan kemiskinan Peserta PKH. Dengan demikian menjadi lancar karena syarat dan ketentuan yang sudah ditentukan di bidang pendidikan (peserta tetap sekolah) dan di bidang kesehatan (tetap penjaminan kesehatan jangka panjang), sehingga bantuan sosial melalui PKH dapat diterima secara tunai oleh Peserta PKH melalui rekening BNI masing-masing Peserta PKM. Selanjutnya Pendamping PKH membantu Peserta PKH untuk mengolah bantuan, dan memberikan penyuluhan kepada Peserta PKH untuk mengembangkan keahlian yang dimiliki oleh masing-masing Peserta PKH. Dengan demikian untuk jangka panjang implementasi PKH dalam upaya pengentasan kemiskinan akan mampu diwujudkan oleh Dinas Sosial Pemerintahan Kota Batu.
\end{abstract}

Keywords: mengolah bantuan, mengembangkan keahlian, mengentaskan kemiskinan 


\section{PENDAHULUAN}

Permasalahan kemiskinan merupakan permasalahan yang dihadapi oleh semua negara, semua provinsi dan semua daerah, kemiskinan muncul karena ketidak berdayaan seseorang untuk memenuhi kebutuhan dasarnya. di Indonesia data dari Badan Pusat Statistik (BPS) disebutkan bahwa indeks kedalaman kemiskinan dan indeks keparahan kemiskinan indonesia periode bulan September Tahun 2016 sampai dengan bulan Maret Tahun 2017 di Indonesia mengalami peningkatan dari aspek angka kemiskinan.

Secara nyata permasalahan data Peserta PKH di lapangan dari hasil verifikasi KSM oleh pendamping masih dijumpai adanya Peserta PKH yang tidak memenuhi syarat, sementara di sisi yang lain ada beberapa masyarakat yang memenuhi syarat sebagai peserta PKH namun justru tidak masuk di data penerima PKH tersebut. Pada instansi terkait perannya belum

maksimal dalam menunjang suksesnya implementasi PKH tersebut, hal ini disebabkan instansi puskesmas dan sekolah merasa berat jika melakukan verifikasi secara terus menerus (continue). Masalah berikutnya yang terjadi adalah implementasi pembayaran PKH tidak tepat waktu, hal ini diakibatkan lambannya verifikasi yang dilakukan pihak terkait.

Masalah selanjutnya masih kurangnya koordinasi yang dilakukan oleh kementerian: Ketenagakerjaan, Pendidikan dan Kebudayaan, dan Kesehatan. Permasalahan berikutnya adalah tidak semua dari Keluarga Sangat Miskin itu menerima jaminan kesehatan, dan tidak semua siswa dari keluarga miskin tersebut menerima bantuan pendidikan.

Hasil survei yang dilakukan oleh Kementrian Keuangan pada bulan september Tahun 2017 yang lalu, bahwa bantuan sosial jenis PKH ini memiliki dampak yang signifikan pada penurunan angka kemiskinan serta ketimpangan, (CNN Indonesia). Oleh karena itu pengentasan kemiskinan melalui PKH ini menjadi prioritas pemerintah Indonesia dan sekaligus menjadi program andalan sebagai upaya pemerintah untuk mengentaskan kemiskinan. Selanjutnya perlu koordinasi dan sinergisitas dan dukungan lintas kementerian seperti : Ketenagakerjaan, Pendidikan dan Kebudayaan, dan Kesehatan. sehingga upaya pemerintah dalam rangka mengentaskan kemiskinan tersebut dapat segera diwujudkan.

\section{KERANGKA TEORITIS}

Implementasi kebijakan adalah tahapan sangat penting dalam keseluruhan struktur kebijakan. Tahap Implementasi menentukan apakah kebijakan yang ditempuh oleh pemerintah benar-benar aplikabel di lapangan dan berhasil menghasilkan output dan outcomes seperti direncanakan. Upaya mewujudkan output dan outcomes yang ditetapkan, maka kebijakan publik perlu diimplementasian. Tanpa implementasi maka kebijakan tersebut hanya akan menjadi catatan-catatan elit sebagaimana dipertegas oleh Udoji (dalam Agustino, 2006) bahwa pelaksanaan kebijakan adalah sesuatu yang penting bahkan mungkin jauh lebih penting daripada pembuatan kebijakan, Kebijakan-kebijakan hanya akan sekedar berupa impian atau rencana bagus yang tersimpan rapi dalam arsip kalau tidak diimplementasikan.

Sejalan dengan pendapat Udoji, George Edward III (dalam Winarno, 2008) berpandangan bahwa implementasi adalah krusial bagi administrasi publik dan kebijakan publik. Implementasi merupakan tahap kebijakan antara pembentukan program dan konsekwensi kebijakan bagi masyarakat yang dipengaruhinya. Apabila suatu program tidak tepat atau tidak bisa mengurangi masalah yang merupakan sasaran kebijakan, maka program itu mungkin akan mengalami kegagalan sekalipun program itu diimplementasikan dengan baik, sedangkan suatu program yang cemerlang mungkin juga akan menghadapi kegagalan bila program tersebut kurang diimplementasikan dengan baik.

George C. Edward III dalam Agustino,

(2012: 149-154) Implementasi menurut Edwards, diartikan sebagai tahapan dalam proses kebijaksanaan yang berada diantara tahapan penyusunan kebijaksanaan dan hasil atau konsekuensi-konsekuensi yang ditimbulkan oleh kebijaksanaan itu (output, outcome). Yang termasuk aktivitas implementasi menurutnya adalah perencanaan, pendanaan, 
pengorganisasian, pengangkatan dan pemecatan karyawan, negosiasi dan lain-lain.

Model ini dikembangkannya, ia mengemukakan ada 4 (empat) faktor kritis yang mempengaruhi keberhasilan atau kegagalan implementasi. Pendekatan yang dilakukan dengan mengajukan pertanyaan :'Prakondisi apa yang harus ada agar implementasi berhasil?" dan

“Apa yang menjadi kendala pokok bagi suksesnya suatu implementasi?"

Ke empat variabel tersebut adalah : 1 . Komunikasi; 2. Sumberdaya; 3. Disposisi atau Sikap Pelaksana; 4. Struktur Birokrasi, yang keseluruhannya saling berhubungan dan saling mempengaruhi satu sama lain dalam menentukan keberhasilan atau kegagalan implementasi.

\section{METODE PENELITIAN}

Metode yang digunakan dalam penelitian ini adalah deskriptif kualitatif. Penentuan sumber data dari: sumber data primer yang diperoleh dari hasil wawancara yang mengaju pada pedoman wawancara yang sudah ditetapkan sebelumnya, sedangkan data sekunder, bersumber pada hasil informasi dari orang kedua, dan dokumentasi yang diperoleh dari Dinas Sosial Kota Batu dan Pendamping PKH. Dalam penelitian ini instrument penelitiannya adalah peneliti sendiri. Teknik penentuan sample dengan menggunakan purposive sampling, data primer juga diperoleh dari observasi, selanjutnya data sekunder diperoleh dari Dokumentasi. Teknik Pengumpulan Data melalui observasi, interview, dokumentasi, menguji dan mengecek data dengan Triangulasi. Analisis data menggunakan model Miles dan Huberman dalam Sugiyono, 2017 yang meliputi: reduksi data, penyajian data, dan verifikasi / kesimpulan.

\section{HASIL DAN PEMBAHASAN Implementasi Program Keluarga Harapan (PKH) Dalam Upaya Mengentaskan Kemiskinan Pada Dinas Sosial Pemerintahan Kota Batu}

1. Komunikasi Implementasi Program Keluarga Harapan (PKH) dalam upaya mengentaskan kemiskinan pada Dinas Sosial Pemerintahan Kota Batu. Komunikasi yang terjalin antara Dinas Sosial, Pendamping PKH dan Peserta PKH pada dasarnya sudah baik dan lancar. Implementasi PKH pada Dinas Sosial Pemerintahan Kota Batu telah bekerjasama dengan Pendamping PKH.

Sejak awal implementasi kebijakan Pendamping $\mathrm{PKH}$ sudah dilibatkan dalam rapat koordinasi, seminar dan matrikulasi untuk membekali pendamping PKH supaya menjadi profesional, di sisi yang lain Dinas Sosial Pemerintahan Kota Batu juga memberikan dukungan yang berupa finansial yakni memberikan bantuan uang jajan dan transpor kepada Pendamping PKH sebesar dua ratus ribu rupiah perpendamping, perbulan. Proses inilah yang merupakan bentuk komunikasi yang dibangun dengan baik dalam implementasi PKH di Kota Batu.

2. Sumber Daya dalam Implementasi Program Keluarga Harapan (PKH) dalam upaya mengentaskan kemiskinan pada Dinas Sosial Pemerintahan Kota Batu melibatkan Pendamping PKH dan Peserta PKH sesuai syarat dan ketentuan di bidang pendidikan dan kesehatan. Besarnya sumber daya keuangan yang diberikan kepada Peserta PKH sebesar lima ratus ribu rupiah setiap orang, setiap bulan.

Temuan di lapangan mayoritas sumber daya Peserta PKH memiliki latar belakang pendidikan yang kurang, sehingga keahlian yang dimiliki Peserta PKM juga sangat kurang, karena keterbatasan kemampuan pendidikan ini tidak jarang

Pendamping sedikit memaksa dan memperingatkan jika syarat dan ketentuan

tidak dipenuhi maka akan kena sangksi/pinalti program akan dihentikan kepada Peserta PKH yang bersangkutan.

Tugas Pendamping PKH yang diberikan oleh Dinas Sosial Pemerintahan Kota Batu adalah mengolah bantuan, serta memberikan penyuluhan kepada Peserta PKH untuk mengembangkan keahlian yang dimiliki oleh Peserta PKH ditengah-tengah keterbatasan pendidikan yang mereka miliki. Dengan demikian untuk jangka panjang PKH mampu mengentaskan kemiskinan di Kota Batu. 
3. Struktur Birokrasi dalam Implementasi Program Keluarga Harapan (PKH) dalam upaya mengentaskan kemiskinan pada Dinas Sosial Kota Batu. Kepala Dinas Sosial memberikan tugas pokok, fungsi dan kewenangan kepada Kepala Bidang Pemberdayaan Bantuan dan Jaminan Sosial, untuk berkoordinasi dengan Pendamping $\mathrm{PKH}$ dalam melaksanakan dan pembinaan kepada Peserta PKH atas syarat dan ketentuan yang ditentukan termasuk juga memberikan sanksi dan pinalti kepada Peserta PKH yang tidak memenuhi syarat dan ketentuan tersebut.

Dinas Sosial Pemerintahan Kota

Batu memberikan tugas kepada Pendamping PKH untuk membantu Peserta PKH dalam mengolah bantuan sebesar lima ratus ribu perorangperbulan, serta memberikan penyuluhan kepada Peserta PKH, dan mengingatkan Peserta PKH akan kewajiban yang harus dipenuhi yakni melengkapi semua syarat dan ketentuan yang sudah ditentukan, seperti di bidang pendidikan (agar peserta tetap sekolah) dan di bidang kesehatan (agar peserta tetap penjaminan kesehatan jangka panjang), setelah semua syarat dan ketentuan ini dipenuhi oleh Peserta PKH, maka selanjutnya bantuan sosial yang diberikan melalui PKH ini dapat diterima secara tunai oleh Peserta $\mathrm{PKH}$ melalui rekening BNI masing-masing Peserta PKH tersebut.

4. Disposisi dalam Implementasi Program Keluarga Harapan (PKH) dalam upaya mengentaskan kemiskinan pada Dinas Sosial Kota Batu. Sikap dan watak aparatur Dinas Sosial, Pendamping PKH dan Peserta PKH secara umum sudah baik, hanya saja ada beberapa Peserta PKH yang kurang baik dari sisi kerjasama dan tanggungjawab khususnya untuk batas akhir pemenuhan syarat dan ketentuan ini yang tidak diperhatikan oleh Peserta PKH, sehingga terlambat dari waktu yang ditentukan, dan berakibat pada mundurnya waktu pencairan dana ke rekening BNI Peserta PKH tersebut.
Sikap dan watak Peserta PKH yang nurut dan patuh terhadap bimbingan dan arahan dari Pendamping $\mathrm{PKH}$ menyebabkan terpenuhinya syarat dan ketentuan secara tepat waktu, pencairan dana PKH tepat waktu sesuai jadual yang ditetapkan, serta tercapainya pengembangan keahlian yang dimiliki oleh Peserta PKH memudahkan Dinas

Sosial Pemerintahan Kota Batu mewujudkan upaya pengentasan kemiskinan di wilayah Kota Batu.

\section{Faktor-Faktor Pendukung Implementasi Program Keluarga Harapan (PKH) Dalam Upaya Mengentaskan Kemiskinan Pada Dinas Sosial Kota Batu}

Komunikasi yang telah terjalin dengan baik antara Pendamping dan Peserta PKH.

Komunikasi tersebut telah memberikan pengetahuan dan pemahaman untuk memenuhi syarat dan ketentuan yang merupakan syarat wajib bagi Peserta PKH sebelum memperoleh hak menerima dana sebagai Peserta PKH di rekeningnya. Dirasakan oleh peserta PKH Dinas selalu melakukan komunikasi dan $\mathrm{PKH}$ dapat memberikan manfaat bagi Peserta PKH untuk memecahkan persoalan hidup sehari-hari mereka.

Sumber Daya yang memadai merupakan sarana pendukung bagi Peserta PKH. Ketika peserta PKH diberikan bantuan pengolahan dana bantuan dan penyuluhan pengembangan keahlian yang disampaikan oleh Pendamping $\mathrm{PKH}$ mendorong potensi keahlian Peserta PKH ini bisa dikembangkan. PKH sudah memberikan manfaat bagi penerima untuk mengentaskan kemiskinan.

\section{Struktur Birokrasi Dinas Sosial} Pemerintahan Kota Batu, yang dipimpin oleh seorang Kepala Dinas Sosial telah mendukung implementasi PKH. Dinas telah mampu mendelegasikan kewenangan kepada Kepala Bidang Pemberdayaan Bantuan dan Jaminan Sosial, untuk mensukseskan PKH. Telah dilakukan berkoordinasi dengan Pendamping PKH dalam melaksanakan dan pembinaan kepada Peserta PKH baik mengenai syarat dan ketentuan yang ditentukan, termasuk ancaman akan sanksi dan pinalti kepada Peserta PKH yang tidak memenuhi syarat dan ketentuan tersebut. 
Disposisi Penerima PKH walaupun sudah dapat bantuan, namun masih diberikan pendampingan. Dinas tetap memberikan pembinaan kepada penerima PKH dalam pengelolaan bantuan, sehingga dapat berjalan terus. Selain itu juga adanya dukungan dari Pemerintahan Daerah Kota Batu melalui Dinas Sosial Pemerintahan Kota Batu yang berupa memberi uang bensin dan uang jajan bagi pendamping PKH. Dinas Sosial Pemerintahan Kota Batu juga mengikutsertakan pendamping dalam kegiatan seminar dan matrikulasi hal ini bertujuan agar menjadikan pendamping lebihprofessional, sehingga Program Keluarga Harapan (PKH) dapat terus berkembang sampai saat ini.

Faktor-Faktor Penghambat Implementasi Program Keluarga Harapan (PKH) Dalam Upaya Mengentaskan Kemiskinan Pada Dinas Sosial Kota Batu sebagai berikut :

Watak dan sikap yang kurang tanggungjawab dari Peserta PKH atas informasi yang diberikan oleh Pendamping PKH. Akibatnya menyebabkan tidak tepatnya waktu penyerahan syarat dan ketentuan dari Peserta PKH, sehingga pencairan dana ke rekening Peserta PKH tidak tepat waktu.

Data di lapangan masih ditemukan adanya data Peserta PKH yang tidak akurat, dimana penerima PKH tersebut tidak memenuhi kriteria yang berrlaku, namun terdaftar pada data sebagai Peserta PKH. Pada sisi yang lain ketika verifikasi oleh Pendamping PKH ditemukan biodata nama tertentu di masyarakat yang kondisinya sangat miskin, dan sangat layak sebagai Penerima $\mathrm{PKH}$, namun orang yang bersangkutan tidak terdaftar di data Kementerian Sosial, maka orang tersebut tidak berhak menerima bantuan sosial dalam Program Keluarga Harapan tersebut.

Ruangan dan fasilitas untuk Pendamping PKH yang terbatas, baik ruangan, meja kursi, komputer dan penunjang lainnya. Kondisi ini dianggap logis saja karena ruangan Pendamping PKH masih jadi satu lokasi dengan Dinas Sosial Pemerintahan Kota Batu.

\section{KESIMPULAN}

Komunikasi; terjalin secara baik antara Dinas Sosial Pemerintahan Kota Batu, Pendamping PKH dan Peserta PKH. Pendamping dilibatkan dalam kegiatan seminar, dan matrikulasi, Pendamping $\mathrm{PKH}$ memberikan penyuluhan tentang syarat dan ketentuan wajib sebagai Peserta PKH. Pendamping PKH juga mendapatkan dukungan finansial berupa uang jajan dan uang trasnport. Peserta PKH berkewajiban memenuhi syarat dan ketentuan yang ditetapkan, sebelum menerima bantuan sosial yang ditransfer melalui rekening BNI Peserta PKH.

Sumber daya; Pendamping PKH diberi tugas membantu Penerima PKH mengolah dana bantuan sosial, yang sudah diterima oleh Peserta PKH.

Struktur Birokrasi; Kepala Dinas Sosial Mendelegasikan kewenangan kepada Kepada Bidang Pemberdayaan Bantuan dan Jaminan Sosial. Selanjutnya menggunakan ruangan dan sarana prasarana Dinas Sosial untuk diperuntukkan menunjang kelancaran PKH di Kota Batu.

Disposisi; sikap dan watak Aparatur Dinas Sosial, Pendamping, dan Peserta PKH sangat berperan dalam suksesnya $\mathrm{PKH}$ dalam upaya mengentaskan kemiskinan di Kota Batu.

Faktor Pendukung: komunikasi yang baik, sumber daya yang profesional, struktur birokrasi yang sudah ada, dan disposisi yang mendukung. Faktor Penghambat: masih adanya sikap dan watak yang apatis Peserta PKH. Data Peserta PKH masih ada yang belum akurat, kapasitas ruangan, sarana dan prasarana, yang terbatas. 


\section{DAFTAR PUSTAKA}

Agustino, Leo. 2006. Dasar-Dasar Kebijakan Publik. Bandung : CV. Alfabeta.

Bungin, M. Burhan. 2007. Penelitian Kualitatif. Jakarta : Prenada Media Group.

Sugiyono, 2017. Metode Penelitian Kualitatif. Untuk Penelitian Yang Bersifat: Eksploratif, Enterpretif, Interaktif Dan Konstruktif. Alfabeta. Bandung.

Solichin AW, 2016. Analisis Kebijakan Dari Formulasi ke Penyusunan Model-
Model Implementasi Kebijakan Publik. Bumi Aksara. Jakarta

Suharto, Edi. 2005. Analisis Kebijakan Publik. Bandung : Alfabeta.

Winarno, Budi. 2007. Kebijakan Publik Teori dan Proses. Yogyakarta : Media Pressindo.

CNN Indonesia, 2017. Program Keluarga Harapan Diklaim Efektif Tekan Kemiskinan. (Online). https://www.cnnindonesia.com/ekono mi 